place them at Ethiopia's mercy. Mutual retaliatory actions between these countries would surely cause widespread harm.

Other countries have agreements for bioprospecting, but these bring mixed benefits. It is not always clear, for example, who owns the intellectual property of the varieties. Brush's forceful conclusion is that increasing ownership will abuse the rights of people who have long been involved in the common pool of genetic resources, but who now find themselves excluded by modern patent laws. Stuart Pimm is in the Nicholas School of the Environment and Earth Sciences, Duke

University, Durham, North Carolina 27708, USA.

\section{Myths and men}

\section{Moments of Truth: Four Creators of Modern Medicine}

by Thomas Dormandy

Wiley: 2004. 576 pp. £18.99, \$30

\section{John Galloway}

To misquote Jane Austen shamelessly: "It is a truth not sufficiently universally acknowledged that information is useful only when it provides evidence for or against some view or proposition." The "moments of truth" of Thomas Dormandy's title are the flashes of insight that propelled four nineteenth-century doctors into the medical pantheon. Théophile Laënnec invented the stethoscope; Ignác Semmelweis put an end to childbed fever; Joseph Lister is credited as the founder of antiseptic surgery; and Walter Reed proved that yellow fever was spread by mosquitoes, laying the foundation for its eradication.

The question here is whether Dormandy's book is just a chronicle of the lives of men whose greatness is already a given, or whether it is more analytical and critical, and makes any judgement on the nature and measure of their greatness. Were they justified in taking — or being given — personal credit for a particular breakthrough in medical science? Or were they each just one of several contributors who all deserved some recognition? I think it is fair to say that Moments of Truth has its feet firmly in the first camp. Dormandy says confidently of his four heroes: "They wrote their own papers and books and signed them without equivocation." They were not team players, then.

I enjoyed this book. The life-and-death business of medicine is well-nigh irresistible, as every fan of TV programmes such as ER or Cardiac Arrest knows. The medical background for Laënnec was tuberculosis, which

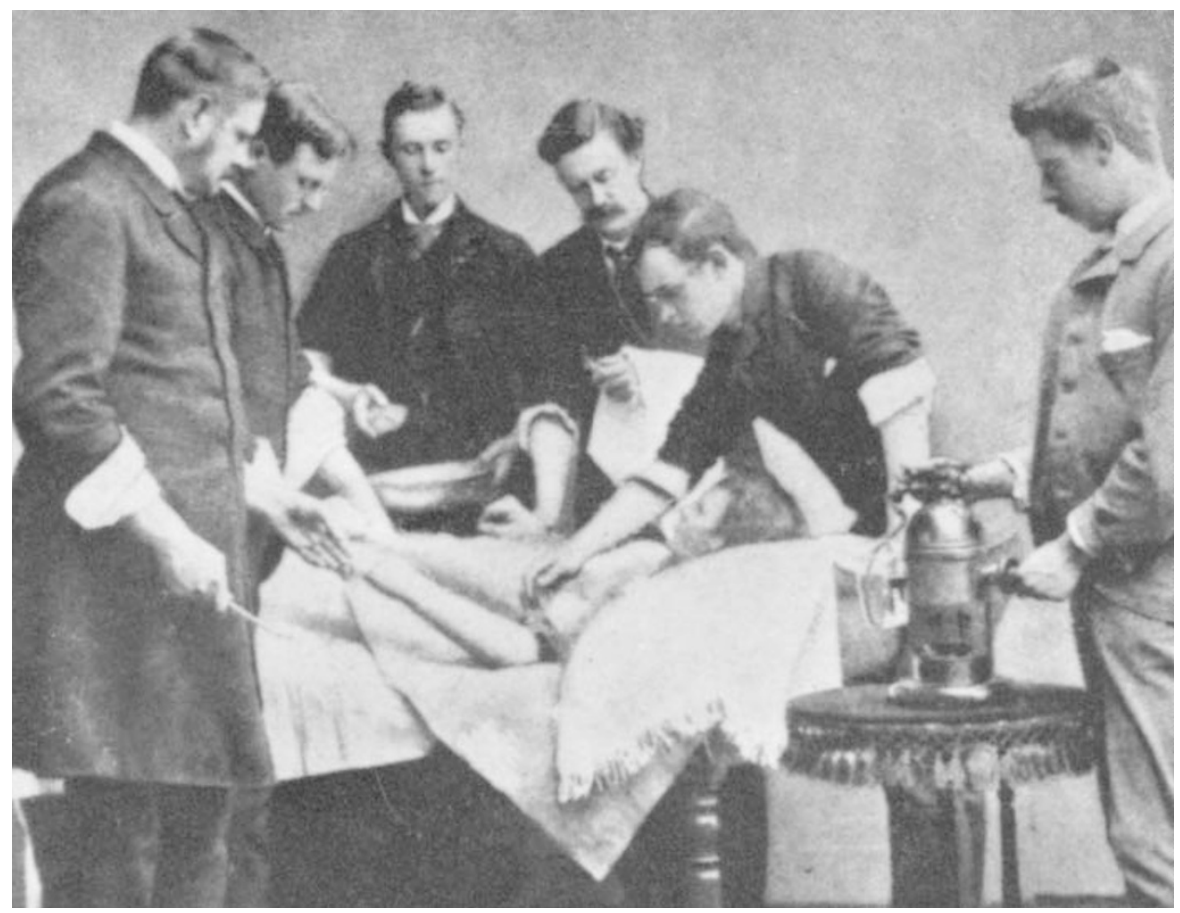

Medical mystery: Théophile Laënnec (below) certainly invented the stethoscope, but how much did Joseph Lister's carbolic acid spray contribute to early antiseptic surgery (above)? killed thousands of people each year in France. Obstetric wards in Vienna, filled with poor pregnant women dying of puerperal fever, were the stamping ground for Semmelweis. Lister's province was the operating theatres of England and Scotland. As the great surgeon James Simpson said: "A patient laid on an operating table in one of our surgical hospitals is exposed to more chances of death than the English soldier on the field of Waterloo." Reed was faced with recurring epidemics of yellow fever among the occupying US troops in Cuba, which killed 20 times as many soldiers as the war. Reed, a military pathologist, headed the commission charged with fighting the disease. For Reed, the larger historical context was crucial in putting him in the right place at the right time, with colleagues who already had a pretty shrewd idea that yellow fever was not directly contagious but spread by mosquitoes - all they lacked was proof.

The stories that Dormandy tells are good, but how do they stand up as history and biography? Novelists, playwrights and journalists recognize one thing above all others: that the essence of drama is that the part (of the hero) is greater than the whole. In real life, however, although individuals do great things, they rarely do them alone. Yet when scientific discovery is presented as drama, it must play down the contribution of others. It is not that they are not mentioned, but rather that they play Rosencrantz and Guildernstern to the great man's Hamlet. We are not given the opportunity to know them as well as we know the central figure. How would the 'moment of truth' look through the lens of the biographies of these minor players, if they were to be written?

Dormandy picks up this point in the book's epilogue but asserts the opposite view, that great discoveries are made only by great individuals, and that no medical scientist illustrates this better than the four men in his book. "Long, long may they flourish," is how he signs off. This presents something of a problem. He decries John Macleod, who shared the Nobel prize with Fred Banting in 1923 for discovering insulin, apparently on the precept that rewarding the unworthy robs the deserving. "He had spent the time of the crucial experiment hunting in the Rockies, unaware that anything interesting was happening in his laboratory." In reality, Charles Best, who worked closely with Banting, was overlooked by the Nobel committee and spent the rest of his life campaigning for recognition. More significantly, arguably the most able member of the team, James Collip, seems to have been written out of the story altogether.

And what about Lister? Was he really the lone genius who ushered in the era of antiseptic surgery single-handedly? Did he then spend 40 years crying in the wilderness, before finally gaining the credit he so richly deserved? Dormandy marshals his facts to give a resounding yes. But some historians think otherwise. They say that the aseptic movement - with its clean wards, bedding 


\section{A measured approach}

\section{Alex Colville's exhaustive search for mathematical probity.}

\section{Martin Kemp}

There is often a point in research of a mathematical nature when the solution to a problem is sensed before it is proved. An anticipatory instinct tells us when something feels right. For someone publishing a scientific paper, the proof is of course essential. For an artist who works towards pictorial solutions, the proof of the pudding is in the viewing, and the instinctual element of 'rightness' remains paramount.

Alex Colville, to my mind the best Canadian artist of his time, works with a slow-burning meditative persistence on the geometrical structures that underlie his pictures. The concept for the picture is triggered by his vision of a pregnant moment in the life of things. The picture shape that 'fits' the subject is then altered by repeated geometrical structuring using complex overlays from Colville's repertoire of inscribed circles, squares, triangles, logarithmic spirals and ratios. Human proportionality, which is based on the system of head lengths beloved of Renaissance architects and more recently Le Corbusier, has an important role in those paintings that involve his cast of wordless characters.

Series of carefully dated studies are made, looking like the storyboard for a film, but destined never to extend in time beyond one enigmatic still. Concentrated flurries of intense design are interspersed with contemplative intervals. Motifs are rearranged and manoeuvred in space, as Colville seeks, for both the mathematical structures and the subject, the right organization of space, the right surface conjunctions and the right intervals. These are neither wholly calculated nor freely instinctual, but a combination of both.

The process behind the picture shown here, The Surveyor, is fairly typical, involving almost 30 drawings over 14 months during 19992000. The surveyor's transit with its splayed tripod is measured for precise transcription. A complex fretwork of lines drawn with straight-edge and compasses is intricately interwoven with the subjects, playing off those constituent parts that are most overtly geometrical with those whose order has been hidden behind the chaos of processes. Scales of head lengths are mapped on the compositional studies. Intricate sets of alternative diagonals structure the complex foreground region anchored by the legs of the tripod and surveyor. Tones and colours are positioned to see what works. All the while, neat calculations of scale keep everything in proportion.

The scene is in Nova Scotia, overlooking the tidal planes near Wolfville, where Colville lives. He is a local painter in the sense that Constable was local, creating art that has to draw nourishment from scenes known intimately in order to find a wider truth. The surveyor, in this case a woman, stands on a ribbon of isolated road, absorbed in the act of measuring. But measuring what? She seems to have turned the precise eye of her instrument on the elusive curves of the tidal waterway, which are always in the process of coming and going.

Colville's art is underpinned by his quest for order from apparent disorder. He searches, like Piero della Francesca in the Renaissance or Georges Seurat in the late nineteenth century, for what we can find beneath and within the surface of appearances if we probe intensively enough. The visual reconstruction of order is hard won and fragile, like the order of society itself. For Colville, the quest, when conducted at the highest level, is a lonely one, drawing on deep resources, yet it is one we recognize and share.

The frame of Piero della Francesca's painting Flagellation (see Nature 390, 128; 1997), in which three mute figures stand in the foreground, closely grouped and emotionally dislocated from the main subject, once bore the inscription, "convenerunt in unum", which roughly means "they conspire together". Colville's art is one of wordless conspiracies in which he enrols us compellingly in his quiet narratives of the apparently ordinary. Below the surface are the strangeness and wonder, disorder and order, that have fired the quests of artists and scientists since the beginning of both art and science.

Martin Kemp is professor of the history of art at the University of Oxford, Oxford OX1 1PT, UK, and co-director of Wallace Kemp Artakt.

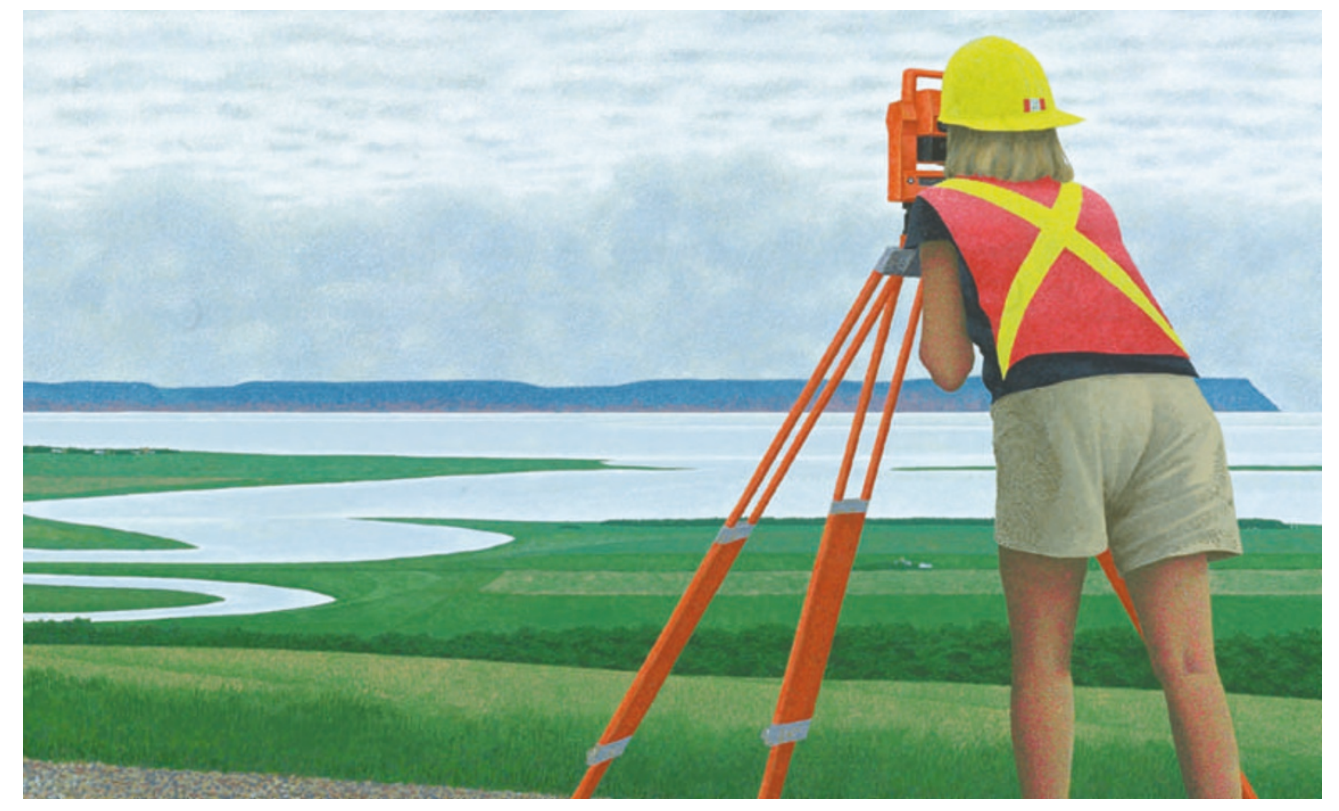

and operating clothes — long pre-dated Lister's spraying of open wounds with carbolic acid, which anyway turned out to be a cul-de-sac rather than the main highway of antiseptic surgery. John Waller has argued forcefully in his own book, Fabulous Science (Oxford University Press, 2002), that Lister was a tireless self-publicist, taking personal credit for a movement he did not start and to which he contributed relatively little.

So, are Dormandy's heroes giants stand- ing on each other's shoulders, or dwarfs treading on each other's toes? Are their stories myth or history? In reality, there is no clear demarcation: it is all down to points of view and motives. After all, one of the functions of myths is to answer questions about origins. Where did medicine come from? Who invented antiseptic surgery? But that is also one of the functions of history. Consider the subtitle of this book, Four Creators of Modern Medicine. However painstakingly collected and scrupulously verified, the real significance of historical 'facts' depends on the quality of the point of view for which they are marshalled. Of course, a point of view may be worth entertaining even if you do not actually accept it on the evidence, and that may depend on how it is put across. In this book, Dormandy puts his across rather well.

John Galloway is at the Eastman Dental Hospital, 256 Gray's Inn Road, London WC1X 8LD, UK. 